\title{
Diagnostic value of post-bronchodilator pulmonary function testing to distinguish between stable, moderate to severe COPD and asthma
}

\author{
Daphne C Richter' \\ James $R$ Joubert ${ }^{1}$ \\ Haylene Nell' \\ Mace M Schuurmans ${ }^{2}$ \\ Elvis M Irusen² \\ 'Tiervlei Trial Centre, Karl Bremer \\ Hospital, Bellville, RSA; ${ }^{2}$ Respiratory \\ Research Unit, Department of Internal \\ Medicine, Faculty of Health Sciences, \\ University of Stellenbosch, RSA
}

\begin{abstract}
Objective: The GOLD guidelines suggest that the presence of a post-bronchodilator forced expiratory volume in one second $\left(\mathrm{FEV}_{1}\right)<80 \%$ of the predicted value in combination with a $\mathrm{FEV}_{1} /$ forced vital capacity $(\mathrm{FVC})<70 \%$ confirms the diagnosis of COPD. Limited data exist regarding the accuracy of these criteria to distinguish between COPD and asthma. The aim of this study therefore was to investigate the diagnostic value of post-bronchodilator lung function parameters in obstructive lung disease.

Methods: The pulmonary function tests of $43(22=$ COPD, $21=$ asthma $)$ patients with similar baseline characteristics were evaluated (baseline $\mathrm{FEV}_{1}$ were $55.7 \% \pm 7.6 \%$, and $59.3 \% \pm 8.4 \%$ predicted for COPD and asthma, respectively). Bronchodilator responsiveness (BDR) was calculated according to three recognized pulmonary function test criteria.

Results: The first criteria, post-bronchodilator $\mathrm{FEV}_{1}<80 \%$ of the predicted value in combination with a post-bronchodilator $\mathrm{FEV}_{1} / \mathrm{FVC}$ ratio of $<70 \%$, had an accuracy of $70 \%$ to diagnose COPD. This combination was very sensitive (100\%) in diagnosing COPD, but it was not specific (38\%). The second BDR criteria, defined as an increase of $<12 \%$ and $200 \mathrm{~mL}$ of initial $\mathrm{FEV}_{1}$ and criterion number 3, an increase of $<9 \%$ of predicted $\mathrm{FEV}_{1}$, were less sensitive ( $55 \%$ and $59 \%$, respectively), but more specific ( $81 \%$ and $76 \%$ respectively) to diagnose COPD. Our findings suggest that the current recommended spirometric indices are not optimal in differentiating between COPD and asthma.
\end{abstract}

Keywords: obstructive lung disease, diagnosis, post-bronchodilator pulmonary function test

\section{Introduction}

COPD and asthma are common conditions and their worldwide prevalence is expected to increase over the next twenty years (Murray and Lopez 1997). Although the two diseases share many clinical features, there are important clinical and pathological differences influencing choice of medication and long-term aims of management (Jeffrey 1998; Celli 2000; Fabri et al 2003).

The degree of reversibility following bronchodilator administration has played a pivotal role in the evaluation of obstructive lung disease, thereby influencing drug choice and patterns of care (Dow 1999). In addition to the clinical importance, bronchodilator testing can have regulatory importance as European regulators now require that COPD patients included in clinical trials meet the ERS definition of irreversible disease (Calverley et al 2003). Significant reversibility is denoted by the American Thoracic Society (ATS) as a change of $>12 \%$ of the baseline forced expiratory volume in one second $\left(\mathrm{FEV}_{1}\right)$ if this also exceeds $200 \mathrm{~mL}$, while the European Respiratory Society (ERS) recommends a change of $>9 \%$ of the predicted $\mathrm{FEV}_{1}$ (American Thoracic Society 1991; Quanjer et al 1993). The numerous ways of expressing BDR have been 
challenged repeatedly (Weir and Burge 1991; Brand et al 1992; Dompeling et al 1992). Although historically used to diagnose asthma, none of these current definitions are sensitive or sufficiently specific to differentiate asthma from COPD purely on spirometric grounds (Meslier et al 1989; Bran et al 1992; Quedrelli et al 1999b).

The GOLD guidelines suggest that the diagnosis of COPD should be confirmed by spirometry. The presence of a post-bronchodilator $\mathrm{FEV}_{1}<80 \%$ of the predicted value in combination with a $\mathrm{FEV}_{1} / \mathrm{FVC}<70 \%$ confirms the presence of airflow limitation that is not fully reversible (Pauwels et al 2001). The usefulness of these post-bronchodilator spirometric variables as diagnostic criteria in BDR testing has to our knowledge not been assessed systematically in patients with obstructive lung disease.

The aim of our study, therefore, was to investigate the accuracy of a number of spirometric criteria used to express the BDR and assess how well they are able to distinguish between COPD and asthma in our study population. We hypothesized that the post-bronchodilator $\mathrm{FEV}_{1}<80 \%$ of the predicted in combination with a $\mathrm{FEV}_{1} / \mathrm{FVC}$ ratio of $<70 \%$ would be more sensitive and specific to distinguish COPD from asthma than the use of ATS and ERS BDR criteria in moderately severe obstructive lung disease.

\section{Methods}

\section{Subjects}

Consecutive subjects with airways obstruction, meeting inclusion criteria as specified below, were prospectively recruited. All participants had to be able to perform technically acceptable pulmonary function tests. Medical histories, including specific respiratory symptoms, were obtained in a standardized manner. Inclusion criteria for the COPD group were a smoking history of more than ten pack years, associated with chronic cough and/or sputum production with an onset of symptoms after 40 years of age. An exclusion criterion for the COPD group was a history of asthma. The asthma group had to be older than 40 years of age with recurrent episodes of wheezing, breathlessness, chest tightness, and coughing, particularly at night or in the early morning. In addition, these subjects had to be ex- or nonsmokers with a less than ten pack year history. All patients had to be clinically stable with no respiratory exacerbations for six weeks prior to inclusion in the study and no changes in chronic medication during this period. Respiratory exacerbations were defined as an increase in breathlessness, sputum volume or sputum purulence from baseline requiring treatment with prednisone and/or antibiotics.
To ensure comparable baseline characteristics, we included only patients with a pre-bronchodilator $\mathrm{FEV}_{1} \%$ predicted of between $40 \%$ and $70 \%$ as well as a $\mathrm{FEV}_{1} / \mathrm{FVC}$ ratio between $45 \%$ and $65 \%$, as the population of moderately severe obstructive lung disease poses the greatest challenge in differentiating COPD from asthma.

\section{Study design}

All subjects signed written informed consent for participation in the study. The local ethics committee approved the study. Bronchodilator treatment was withdrawn prior to pulmonary function testing according to standard practice (immediate release theophylline: 24 hours, long acting $\beta_{2}$-agonist: 12 hours, short acting $\beta_{2}$-agonist: 6 hours and short acting anticholinergic: 8 hours).

\section{Procedures}

A qualified pulmonary technologist conducted maximal in-and expiratory flow volume curves with subjects seated before ('pre') and after ('post') administration of $400 \mu \mathrm{g}$ salbutamol. The medication was given via a metered dose inhaler with a large volume spacer (Volumatic, GlaxoSmithKline). ATS guidelines (1994) were adhered to concerning spirometric assessments, calibration and equipment maintenance. All pulmonary function measurements were made using a Jaeger Masterscope 4.0 spirometer (Würzburg, Germany). Predicted normal values were calculated as laid down by the European Community for Coal and Steel (ECCS). For analysis, the best $\mathrm{FEV}_{1}$ and forced vital capacity (FVC) were chosen regardless of the curve. The 'best test' curve was selected from the largest sum of $\mathrm{FEV}_{1}$ and FVC. All other lung function parameters selected for analysis were taken from the 'best test' curve.

\section{Evaluation of bronchodilator response}

Bronchodilator responsiveness (BDR) was calculated according to the following three criteria: 1) $\mathrm{FEV}_{1}$ postbronchodilator $<80 \%$ predicted and $\mathrm{FEV}_{1} / \mathrm{FVC}$ ratio $<70 \%, 2$ ) $\mathrm{FEV}_{1}$ change from initial $\left(\mathrm{FEV}_{1} \% \Delta\right.$ init: post $\mathrm{FEV}_{1}-$ pre $\mathrm{FEV}_{1} /$ pre $\mathrm{FEV}_{1} \times 100$ ) less than $12 \%$ and $\mathrm{FEV}_{1}$ absolute change $\left(\mathrm{FEV}_{1}\right.$ abs $\Delta$ : post $\mathrm{FEV}_{1}$ - pre $\left.\mathrm{FEV}_{1}\right)$ less than $200 \mathrm{~mL}$ (according to ATS guidelines) (American Thoracic Society $1991)$ and 3$) \mathrm{FEV}_{1}$ change from predicted $\left(\mathrm{FEV}_{1} \% \Delta\right.$ pred: post $\mathrm{FEV}_{1}$-pre $\mathrm{FEV}_{1} /$ predicted $\mathrm{FEV}_{1} \times 100$ ) less than $9 \%$ (according to ERS guidelines) (Quanjer et al 1993).

\section{Data analysis}

Results are presented as means \pm standard error of mean. A p value of $<0.05$ was considered significant. Descriptive 
group data were compared using the unpaired student t-test. Differences among the groups were evaluated using analysis of variance (ANOVA). The sensitivity and specificity as well as the predictive values and accuracy of a BDR to salbutamol in distinguishing patients with COPD and asthma were calculated for the three criteria as outlined above.

\section{Results}

\section{Subject characteristics}

104 patients with COPD and 127 patients with asthma were evaluated consecutively. 22 COPD and 21 asthma patients with a baseline $\mathrm{FEV}_{1}$ of $55.7 \% \pm 7.6 \%$, and $59.3 \% \pm 8.4 \%$ predicted respectively met the inclusion criteria and were included for further analyses.

Subject characteristics are outlined in Table 1. The COPD and asthma groups had comparable baseline pre-bronchodilator pulmonary function tests and demographics.

Table I Baseline pre-bronchodilator subject characteristics

\begin{tabular}{|c|c|c|}
\hline & COPD & Asthma \\
\hline Subjects $n$ & 22 & 21 \\
\hline $\mathrm{F}: \mathrm{M}$ & 13:9 & $11: 10$ \\
\hline Age yrs & $52.2(1.15)$ & $50.1(1.44)$ \\
\hline Pack years & $43.8(2.9)$ & 0 \\
\hline \multicolumn{3}{|l|}{ Medication } \\
\hline Short acting $\beta_{2}$-agonist & $22(100 \%)$ & $21(100 \%)$ \\
\hline Short acting anticholinergic & $15(68 \%)$ & $6(29 \%)$ \\
\hline Long acting $\beta_{2}$-agonist & $5(23 \%)$ & 0 \\
\hline Long acting anticholinergic & 0 & 0 \\
\hline Inhaled corticosteroid & $9(4 \mid \%)$ & $21(100 \%)$ \\
\hline Theophylline & $8(36 \%)$ & 0 \\
\hline Height $\mathrm{cm}$ & $1.64(0.18)$ & $1.68(0.02)$ \\
\hline Weight kg & $69.23(3.56)$ & $79.61(2.78)^{*}$ \\
\hline BMI kgm² & $25.6(1.25)$ & $28.1(0.94)$ \\
\hline \multicolumn{3}{|l|}{ Spirometry } \\
\hline $\mathrm{FEV}_{1} \mathrm{~L}$ & $1.57(0.10)$ & $1.80(0.10)$ \\
\hline \%pred & $55.74(1.63)$ & $59.29(1.82)$ \\
\hline FVC L & $2.82(0.16)$ & $3.17(0.18)$ \\
\hline \%pred & $83.5(1.98)$ & $86.5(2.74)$ \\
\hline $\mathrm{FEF}_{50} \mathrm{~L}$ & $0.90(0.07)$ & $1.05(0.06)$ \\
\hline \%pred & $21.79(1.52)$ & $24.45(1.24)$ \\
\hline $\mathrm{FEV}_{\mathrm{l}} / \mathrm{FVC} \%$ & $55.74(0.99)$ & $57.65(1.16)$ \\
\hline
\end{tabular}

Abbreviations: COPD, chronic obstructive pulmonary disease; F, female; M, male; BMI, body mass index; $\mathrm{FEV}_{\text {, }}$, forced expiratory volume in one second; $\mathrm{FVC}$, forced vital capacity; $\mathrm{FEF}_{50}$, forced expiratory flow at $50 \%$ of FVC; \%pred, percentage of predicted.

Notes: Data are presented as mean \pm SEM. Spirometric comparisons between groups were made only between \% pred normal values.

$*_{p}<0.05$, significant difference between groups.
All subjects were on short acting $\beta_{2}$-agonist therapy. 9 (41\%) COPD patients were on inhaled or oral corticosteroids, 5 (23\%) were on long acting $\beta_{2}$-agonist therapy and $8(36 \%)$ were on theophylline. All asthmatic patients were on inhaled steroids. No asthmatic patient was on oral steroids, theophylline or long acting $\beta_{2}$-agonist therapy. Subgroup analysis showed that corticosteroid treatment did not significantly influence bronchodilator response within the COPD group ( $\mathrm{p}<0.07$, data not shown).

\section{Bronchodilator responses}

Spirometric changes in response to salbutamol are shown in Table 2. After salbutamol inhalation there was a statistically significant increase of all flow volume curve parameters in both groups. The mean responses were significantly greater for the asthma group for all the $\mathrm{FEV}_{1}$ criteria (Table 2). The absolute change in FVC after bronchodilator administration was significantly greater in the asthma subjects in comparison to the COPD group (Table 2). The $\mathrm{FEF}_{50}$ showed a significant response to salbutamol in the asthma patients, but not in the subjects with COPD (Table 2). The pre- and post-bronchodilator $\mathrm{FEV}_{1} / \mathrm{FVC}$ ratio remained almost the same in the COPD group, whereas in comparison the ratio increased significantly $(p=0.003)$

Table 2 Responses to $400 \mu \mathrm{g}$ salbutamol metered dose inhaler

\begin{tabular}{|c|c|c|}
\hline & COPD & Asthma \\
\hline \multicolumn{3}{|l|}{ FEV } \\
\hline \%pred (post bd) & $63(1.5)$ & $75(2.1)^{* *}$ \\
\hline$\% \Delta$ init & $13(3)$ & $27(3)^{* *}$ \\
\hline$\% \Delta$ pred & $7(2)$ & $15(2)^{* *}$ \\
\hline $\operatorname{abs} \Delta \mathrm{L}$ & $0.185(0.04)$ & $0.445(0.03)^{* * *}$ \\
\hline \multicolumn{3}{|l|}{ FVC } \\
\hline \%pred (post bd) & $90(3)$ & 97 (3) ns \\
\hline$\% \Delta$ init & $8(3)$ & $13(2) \mathrm{ns}$ \\
\hline$\% \Delta$ pred & $6(2)$ & II (2) ns \\
\hline $\operatorname{abs} \Delta \mathrm{L}$ & $0.193(0.07)$ & $0.375(0.05)^{*}$ \\
\hline \multicolumn{3}{|l|}{$\mathrm{FEF}_{50}$} \\
\hline \%pred (post bd) & $25(2)$ & $36(2)^{* * *}$ \\
\hline$\% \Delta$ init & $18(6)$ & $52(6)^{* *}$ \\
\hline$\% \Delta$ pred & $4(1)$ & $12(1)^{* * *}$ \\
\hline $\operatorname{abs} \Delta \mathrm{L}$ & $0.151(0.05)$ & $0.492(0.05)^{* * *}$ \\
\hline FEV,/FVC (post bd) & $58(2)$ & $64(1)^{*}$ \\
\hline
\end{tabular}

Abbreviations: $\mathrm{FEV}_{1}$, forced expiratory volume in one second; FVC, forced vital capacity; $\mathrm{FEF}_{50}$, forced expiratory flow at $50 \%$ of $\mathrm{FVC}$; $\%$ pred, percentage of predicted; $\% \Delta$ init, percentage change from initial; $\% \Delta$ pred, percentage change from predicted; abs $\Delta$, absolute change.

Note: Data are presented as mean \pm SEM

${ }^{*} p<0.01, p<0.001, p<0.0001$, significant difference in COPD versus asthma groups. 
in the asthma group (Figure 1). The post bronchodilator $\mathrm{FEV}_{1} \%$ predicted was significantly $(\mathrm{p}=0.0002)$ lower in the COPD group (Figure 1). All COPD and $13(62 \%)$ of asthma patients fulfilled the first tested BDR criteria $\left(\mathrm{FEV}_{1}\right.$ post-bronchodilator $<80 \%$ predicted and $\mathrm{FEV}_{1} / \mathrm{FVC}$ ratio $<70 \%$ ). 12 (55\%) COPD and 4 (19\%) Asthma patients had a positive response according to the second criteria of a BDR $<12 \%$ and $\mathrm{FEV}_{1}$ absolute change $<200 \mathrm{~mL}$. The third BDR criteria, $\mathrm{FEV}_{1}$ change from predicted $<9 \%$, was fulfilled in 13 (59\%) COPD and 5 (24\%) asthma patients. There was a significant difference between the two groups in the FEV bronchodilator response when expressed as a percentage of the initial value $(p=0.001)$ as well as for the change from predicted criteria $(p=0.0003)$ (Figure 2$)$.

The sensitivity, specificity, predictive values and accuracy of diagnosing COPD for each of the three BDR criteria, as defined above, are given in Table 3. Although the first criteria tested $\left(\mathrm{FEV}_{1}\right.$ post-bronchodilator $<80 \%$ predicted and $\mathrm{FEV}_{1} / \mathrm{FVC}$ ratio $<70 \%$ ) proved to be the most sensitive $(100 \%)$ to diagnose COPD, it was the least specific $(38 \%)$ criteria to rule out asthma. The second (BDR $<12 \%$ and $\mathrm{FEV}_{1}$ absolute change $<200 \mathrm{~mL}$ ) and third (FEV1 change from predicted $<9 \%$ ) criteria had a specificity of $81 \%$ and $76 \%$ respectively with a sensitivity of $55 \%$ and $59 \%$ respectively.

\section{Discussion}

Although previous studies have examined the ability of different BDR indices to distinguish between COPD and asthma, the diagnostic value of the post-bronchodilator $\mathrm{FEV}_{1} /$ $\mathrm{FVC}$ ratio and $\mathrm{FEV}_{1}>80 \%$ predicted have to our knowledge not been assessed systematically in a group of obstructive lung disease patients with comparable baseline lung function severity. Our data suggest that the post-bronchodilator $\mathrm{FEV}_{1}>80 \%$ predicted in combination with a post-bronchodilator $\mathrm{FEV}_{1} /$ FVC ratio $>70 \%$ are more sensitive in diagnosing COPD, but it is less specific than the current ATS and ERS BDR indices (BDR $<12 \%$ and $\mathrm{FEV}_{1}$ absolute change $<200 \mathrm{~mL}$ or FEV1 change from predicted $<9 \%$ ) (American Thoracic Society 1991; Quanjer et al 1993).

The usefulness of classifying patients based on their response to bronchodilator administration has significant limitations (Calvery et al 2003). The evaluation of therapeutic efficacy needs to be reassessed and the traditional reliance on an improved post-bronchodilator $\mathrm{FEV}_{1}$ has clear limitations (Pellegrino et al 1993; O'Donnell 2000). The use of exercise

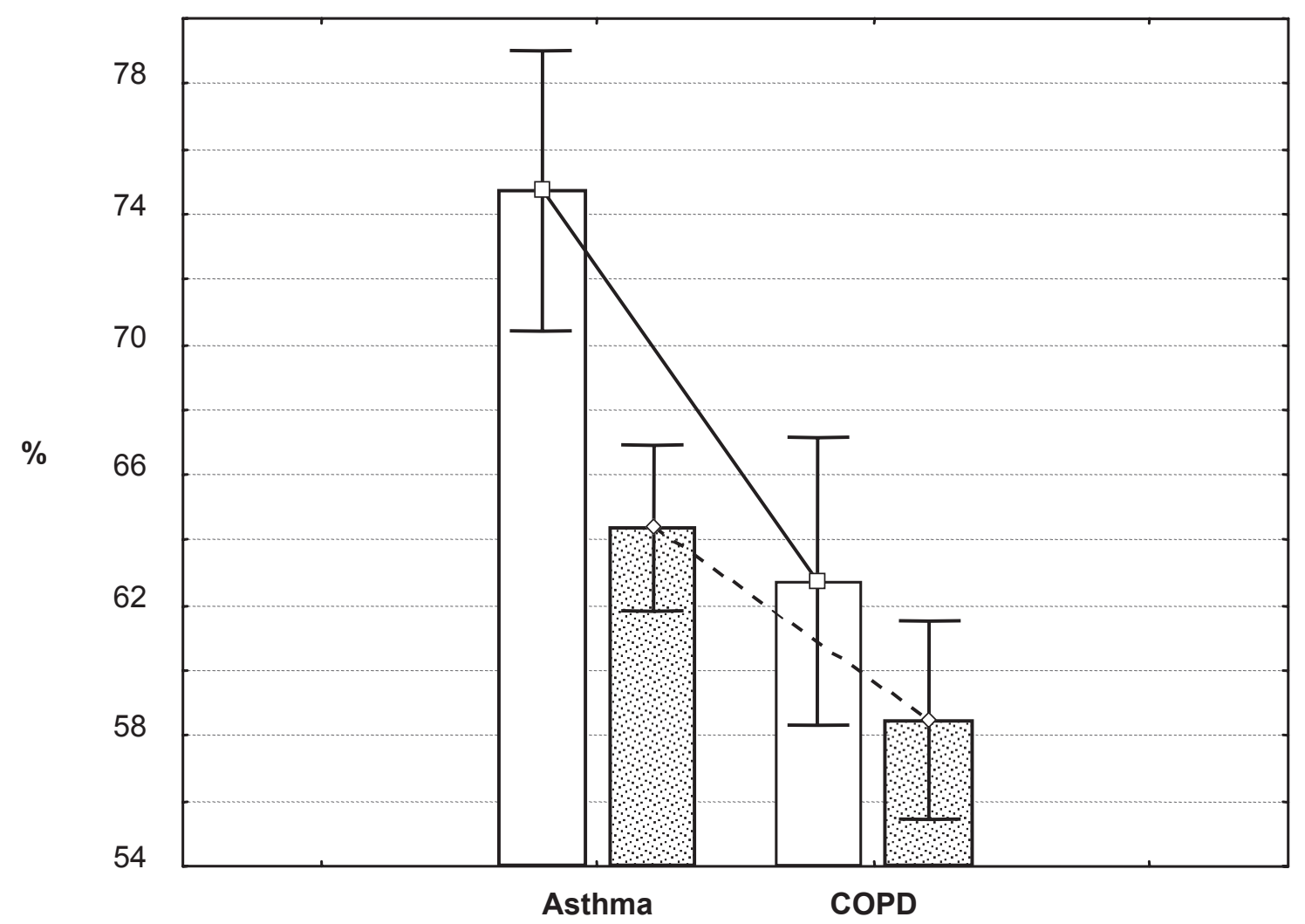

Figure I Post bronchodilator FEV, \% predicted (타) and FEV,/FVC ratio (뼈) with horizontal bars indicating confidence limits for means at $95 \%$ confidence interval. 


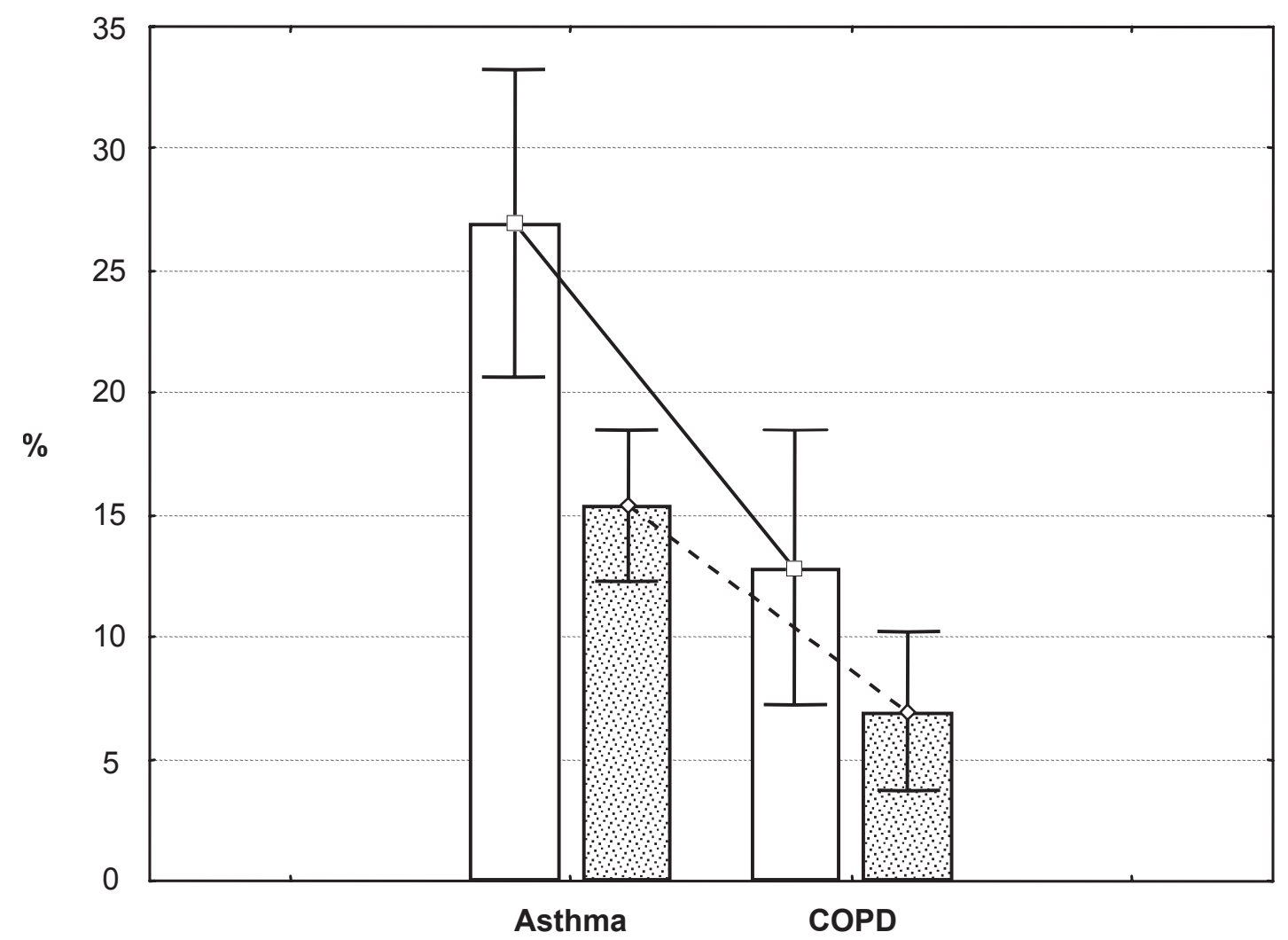

Figure 2 Bronchodilator response expressed as an increased percentage from initial $\mathrm{FEV}_{1}\left(\right.$ (파) and as an increase percentage from the predicted $\mathrm{FEV}_{1}$ (四). Horizontal bars indicate confidence limits for means at $95 \%$ confidence interval.

testing with reliable subjective measurements of dyspnea and quality of life has been found to be more sensitive to adequately predict a positive clinical response to bronchodilator therapy, but this comprehensive therapeutic assessment of bronchodilator efficacy may not be feasible for many clinicians managing COPD (O’Donnell 2000). An additional advantage of the $\mathrm{FEV}_{1} / \mathrm{FVC}$ fixed ratio could be that only one post-bronchodilator flow volume curve is required, and the need for calculation of a BDR is eliminated, which means that this approach would be timesaving and less susceptible to calculation errors.

It is known that the BDR is significantly influenced by the degree of baseline impairment when expressed as a percentage of the initial flow volume curve value (Eliasson and Degraff 1985; Calverley et al 2003). Despite the fact that patients with more severe obstruction will show a greater improvement than patients with a higher baseline value, this criteria is still used at times as part of the inclusion or exclusion criteria for pharmaceutical trials, and it can lead to inaccurate clinical diagnoses affecting patient management. Due to this well known fact we chose to include only patients with comparable baseline lung function impairment. This inclusion criterion resulted in relatively low numbers of patients ultimately included in the final analysis and this could be a possible limitation of our study.

Instead of looking at degrees of reversibility that exceed arbitrary thresholds, a more useful feature for confirmation of COPD is that the patient's lung function does not return to normal after bronchodilator administration (Calverley and Walker). Unfortunately when applying the GOLD criteria in our group of obstructive lung disease patients $62 \%$ of the asthma patients fulfilled the diagnosis for COPD purely on spirometric grounds. It is a well known fact that a percentage of patients with chronic severe asthma have persistent airflow obstruction (Bumbacea et al 2003).

In our study population, there was a significantly greater improvement in $\mathrm{FEF}_{50}$ in the asthma group compared to the COPD group (Table 2). This sensitive parameter may be useful for long term studies in individuals when onset of disease is sought (Cochrane et al 1977). It is, however, not recommended for routine assessment of the BDR due to intra-individual variability (Knudson et al 1983).

Despite the inherent interdependence of $\mathrm{FEV}_{1}$ and $\mathrm{FVC}$, we found a differential response of the $\mathrm{FEV}_{1} / \mathrm{FVC}$ ratio between the two groups (Figure 1). Due to a greater FEV compared to FVC response in the asthma group (Table 2), 
Table 3 Sensitivity, specificity, predictive values and accuracy of each lung function criteria to diagnose COPD based on the bronchodilator response

\begin{tabular}{|c|c|c|c|c|c|c|}
\hline $\begin{array}{l}\text { Lung function } \\
\text { criteria }\end{array}$ & $\begin{array}{l}\text { Cutoff } \\
\text { level }\end{array}$ & Sensitivity \% & Specificity \% & $\begin{array}{l}\text { Positive } \\
\text { predictive } \\
\text { value, \% }\end{array}$ & $\begin{array}{l}\text { Negative } \\
\text { predictive } \\
\text { value, \% }\end{array}$ & Accuracy \% \\
\hline $\begin{array}{l}\text { Post bronchodilator } \\
\mathrm{FEV}_{1} / \mathrm{FVC} \% \text { and FEV, } \\
\% \text { pred }\end{array}$ & $<70 \%$ and $80 \%$ & 100 & 38 & 63 & 100 & 70 \\
\hline $\mathrm{FEV}, \% \Delta$ init and $\Delta$ abs & $<12 \%$ and $200 \mathrm{~mL}$ & 55 & 81 & 75 & 63 & 67 \\
\hline $\mathrm{FEV}_{1} \% \Delta$ pred & $<9 \%$ & 59 & 76 & 72 & 64 & 67 \\
\hline
\end{tabular}

Abbreviations: $\mathrm{FEV}_{1}$, forced expiratory volume in one second; FVC, forced vital capacity; \% $\Delta$ init, percentage change from initial; abs $\Delta$, absolute change; $\% \Delta$ pred, percentage change from predicted; \% pred, percentage of predicted.

the $\mathrm{FEV}_{1} / \mathrm{FVC}$ ratio significantly $(p=0.003)$ increased in the asthma group, but remained low in the COPD group after bronchodilatation. On close examination of previously published results it is interesting to note that the FVC response appears to be generally greater than the $\mathrm{FEV}_{1}$ response in COPD patients, but the inclusion criteria for these studies varied considerably, and no mention is made of the significance of the differences observed (Calverley et al 2003; Newton et al 2002). The choice of lung function tests for a given purpose should take into consideration the degree of variability of that test if the interpretation is not to be misleading (McCarthy et al 1975). Tweeddale and colleagues (1987) found that the increase in $\mathrm{FEV}_{1}$ and FVC that excluded natural variability with $95 \%$ confidence in patients with obstructive ventilatory defects was $160 \mathrm{~mL}$ and $330 \mathrm{~mL}$ respectively. Whether these values are applicable for both COPD and asthma was not specified in that study. Despite this inherent difference between these two lung function parameters, the ATS guidelines suggest an increase after bronchodilator administration of more than $200 \mathrm{~mL}$ in either $\mathrm{FEV}_{1}$ or $\mathrm{FVC}$ to be significant which may lead to diagnostic misclassification (American Thoracic Society 1991).

The post-bronchodilator $\mathrm{FEV}_{1}>80 \%$ predicted parameter has the disadvantage of requiring a set of predicted values applicable to a specific population group, making comparison of international studies difficult. Using a fixed percentage of the predicted value as the lower limit of normal can therefore result in inappropriate classification of patients (Quedrelli et al 1999a).

Using a fixed $\mathrm{FEV}_{1} / \mathrm{FVC}$ ratio as the lower limit of normal has recognized limitations (Knudson et al 1983; American Thoracic Society 1991). It has, however, been suggested by some authors to offer certain benefits as a compromise solution among competing definitions of obstruction, in that the fixed ratio is easy to remember and does not require the use of population specific reference tables (Celli et al 2003). This assumption remains to be verified in large population based studies. It cannot be emphasized enough that no single spirometric parameter or index will take the place of clinical evaluation in diagnosing patients with COPD or asthma, but spirometry is supplementary and remains the objective cornerstone (Pauwels et al 2001). Agreement should be reached internationally on the spirometric evaluation of patients with obstructive lung disease. Different criteria used to define obstruction and reversibility will result in vastly different prevalence rates of obstructive lung diseases in the general population and it complicates international comparisons of studies (Viegi et al 2000; Celli et al 2003). It is time that the appropriateness of definitions used to date is reconsidered.

The lung function data for each patient on our study can be seen as a snap shot and longitudinal reevaluation would have been ideal. Fluctuation in airway function is a well known fact, and it has to be taken into account in the evaluation of patients that the lungs are a complex and dynamic system. Acute bronchodilator response has limited value in differentiating bronchial asthma from COPD (Chhabra 2005). It does not help that the guidelines focuses on post bronchodilator $\mathrm{FEV}_{1}$ for COPD and pre bronchodilator values for asthma when it comes to classification of disease severity (Sterk 2004).

In an attempt to keep the groups clinically diagnosed with COPD or asthma as "pure" as possible, we did not include asthmatic smokers, patients with known combined disease or patients with COPD in the absence of a strong smoking history. The selection criteria of COPD and asthma patients could therefore potentially be seen as artificial. All of these 
groups would warrant special attention in clinical practice, but for the purposes of the article it was impossible to include them.

In our study population the post-bronchodilator $\mathrm{FEV}_{1}<80 \%$ predicted in combination with the $\mathrm{FEV}_{1} / \mathrm{FVC}$ ratio value $>70 \%$ (criteria $\# 1$ ) was very sensitive $(100 \%$ ) in diagnosing COPD. Unfortunately the criteria were unable to distinguish reliably between patients with COPD and asthma as $62 \%$ of asthmatic patients did not achieve "normal" spirometry in the stage of obstructive lung disease studied here. The conventional BDR criteria (criteria \#2 $\mathrm{FEV}_{1}<12 \%$ and absolute change $<200 \mathrm{~mL}$, criteria \#3 $\mathrm{FEV}_{1}$ change from predicted $<9 \%$ ) were specific, because a smaller percentage of asthma patients fell below the historically selected positive BDR response criteria, but it was less sensitive due to the positive BDR response in the COPD patients as well. It might be a good idea to combine the GOLD criteria (criteria \#1) as well as the conventional BDR criteria (criteria \#2) to increase the accuracy. In summary, asthmatic subjects show more reversibility than COPD subjects even when they have post-BD airflow obstruction. Adding the bronchodilator test in the diagnoses of COPD (GOLD) guidelines could help to reduce the misclassification of asthmatics with COPD.

In the evaluation of obstructive lung disease spirometry remains an investigative tool to confirm a clinical suspicion. Additional meaningful outcome measures are urgently needed to accurately distinguish between COPD and asthma.

\section{Conflict of interest}

The authors report no conflict of interest.

\section{References}

American Thoracic Society. 1991. Lung function testing: selection of reference values and interpretative strategies. Am Rev Respir Dis, 144:1202-18.

American Thoracic Society. 1994. Standardization of spirometry: 1994 update. Am J Respir Crit Care Med, 152:1107-36.

Brand PLP, Quanjer PH, Postma DS, et al. 1992. Interpretation of bronchodilator response in patients with obstructive airways disease. Thorax, 47:429-36.

Bumbacea D, Campbell D, Nguyen L, et al. 2004. Parameters associated with persistent airflow obstruction in chronic severe asthma. Eur Respir J, 24:122-8.

Calverley PMA, Burge PS, Spencer S, et al. 2003. Bronchodilator reversibility testing in chronic obstructive pulmonary disease. Thorax, 58:659-64.

Calverley PMA, Walker P. 2003. Chronic obstructive pulmonary disease. Lancet, 362:1053-61.

Celli BR, Halbert RJ, Isonaka S, et al. 2003. Population impact of different definitions of airway obstruction. Eur Respir J, 22:268-73.

Celli BR. 2000. The importance of spirometry in COPD and asthma. Effect on approach to management. Chest, 117:15-9.
Chhabra SK. 2005. Acute bronchodilator response has limited value in differentiating bronchial asthma from COPD. J Asthma, 42:367-72.

Cochrane GM, Prieto F, Clark TJH. 1977. Intrasubject variability of maximal expiratory flow volume curve. Thorax, 32:171-6.

Dompeling E, van Schayck CP, Molema J, et al. 1992. A comparison of six different ways of expressing the bronchodilating response in asthma and COPD; reproducibility and dependence of prebronchodilator FEV $\mathrm{FV}_{1}$. Eur Respir J, 5:975-81.

Dow L.1999. Asthma versus chronic obstructive pulmonary disease exploring why "reversibility versus irreversibility" is no longer an appropriate approach. Clin Exp Allergy, 29:739-43.

Eliasson O, Degraff AC. 1985. The use of criteria for reversibility and obstruction to define patient groups for bronchodilator trials. Influence of clinical diagnosis, spirometric and anthropometric variables. Am Rev Respir Dis, 132:858-64.

Fabbri LM, Romagnoli M, Corbetta L, et al. 2003. Differences in airway inflammation in patients with fixed airflow obstruction due to asthma or chronic obstructive pulmonary disease. Am J Respir Crit Care Med, 167:418-24.

Jeffrey PK. 1998. Structural and inflammatory changes in COPD: a comparison with asthma. Thorax, 53:129-36.

Knudson RJ, Lebowitz MD, Holberg CJ. 1983. Changes in the normal expiratory flow-volume curve with growth and aging. Am Rev Respir Dis, 127:725-34.

McCarthy DS, Craig DB, Cherniack RM. 1975. Intraindividual variability in maximal expiraoty flow-volume and closing volume in asymptomatic subjects. Am Rev Respir Dis, 112:407-11.

Meslier N, Racineux JL, Six P, et al. 1989. Diagnostic value of chronic obstruction to separate asthma from chronic bronchitis: a statistical approach. Eur Respir J, 2:497-505.

Murray CJL, Lopez AD. 1997. Alternative projections of mortality and disability by cause 1990-2020. Global Burden of Disease Study. Lancet, 349:1498-504.

Newton MF, O’Donnell DE, Forkert L. 2002. Responses of lung volumes to inhaled salbutamol in a large population of patients with severe hyperinflation. Chest, 121:1042-50.

O'Donnell DE. 2000. Assessment of bronchodilator efficacy in symptomatic COPD. Is spirometry useful? Chest, 117:42-7.

Pauwels RA, Buist AS, Calverley PM, et al. 2001. Global strategy for the diagnosis, management and prevention of chronic obstructive pulmonary disease. NHLBI/WHO Global Initiative for Chronic Obstructive Lung Disease [GOLD] Workshop summary. Am J Resp Crit Care Med, 163:1256-76.

Pellegrino R, Rodarte JR, Brusasco V. 1998. Assessing the reversibility of airway obstruction. Chest, 114:1607-12.

Quanjer PH, Tammeling GJ, Cotes JE, et al. 1993. Lung volumes and forced ventilatory flows. Report Working Party Standardization of Lung Function Tests, European Community for Steel and Coal. Official Statement of the European Respiratory Society. Eur Respir J, $6: 5-40$.

Quedrelli SA, Roncoroni AJ, Montiel GC. 1999a. Assessment of respiratory function: influence of spirometry reference values and normality criteria selection. Respir Med, 93:523-35.

Quedrelli SA, Roncoroni AJ, Montiel GC. 1999b. Evaluation of bronchodilator response in patients with airway obstruction. Respir Med, 93:630-6.

Sterk PJ. 2004. Let's not forget: the GOLD criteria for COPD are based on post-bronchodilator $\mathrm{FEV}_{1}$. Eur Respir J, 23:497-8.

Tweeddale PM, Alexander F, McHardy GJR. 1987. Short term variability in $\mathrm{FEV}_{1}$ and bronchodilator responsiveness in patients with obstructive ventilatory defects. Thorax, 42:487-90.

Viegi G, Pedreschi M, Pistelli F, et al. 2000. Prevalence of airways obstruction in a general population. European Respiratory Society vs American Thoracic Society definition. Chest, 117:339-45.

Weir DC, Burge PS. 1991. Measures of reversibility in response to bronchodilators in chronic airflow obstruction: relation to airway caliber. Thorax, 46:43-5. 
